\title{
PENGARUH METODE DEMONSTRASI DAN METODE DRILL TERHADAP HASIL BELAJAR MATEMATIKA DI SD CENDERAWASIH 2 JAKARTA
}

\author{
Dewi Purnama Sari ${ }^{1)}$, Nurullita Sari' \\ ${ }^{1}$ Program Studi Matematika, FMIPA-Universitas Pamulang \\ Email: dosen01569@unpam.ac.id \\ ${ }^{2}$ Program Studi Matematika, FMIPA-Universitas Pamulang \\ Email: dosen02122@unpam.ac.id
}

\begin{abstract}
The Covid-19 pandemic has changed all fields, one of which is education. Teachers and students are required to learn from home through online learning, this has an effect on self-confidence in learning. This research is motivated by the many findings of decreasing mathematics learning outcomes of students from the results of initial research observations. So this research was conducted with the aim of knowing the effect of using demonstration learning methods and drill methods.

SD Cenderawasih 2 Jakarta, grade IV, even semester of the 2019-2020 school year as a place to conduct research. The experimental method used in this research. The study population was all fourth grade students, then the sample was chosen randomly. The experimental class consisted of 30 samples and a control class of 30 students. The research instrument has been tested for validity with the Point Biserial Correlation formula obtained 30 valid questions and reliability tests, while the reliability test using KR-20 is obtained. Both data were subjected to further tests, namely normality and homogeneity tests. The results of the normality test in the experimental class were obtained while the control class, so that the two samples could be concluded that they were normally distributed. The results of the calculation of the homogeneity test are generated, so that the two classes can be concluded to have homogeneous variances. The results of hypothesis testing with the t-test obtained a significance level of $\alpha=0.05$ and degrees of freedom $(d k)=58$. So reject $H_{0}$, so the research results conclude that there is an influence on the results of learning mathematics using the demonstration method and the drill method.
\end{abstract}

Keywords: demonstration method, drill method, students' mathematics learning outcomes

\begin{abstract}
ABSTRAK
Pandemi Covid-19 telah mengubah semua bidang salah satunya dibidang pendidikan. Guru dan siswa dituntut untuk belajar dari rumah melalui pembelajaran online, hal ini berpengaruh pada rasa percaya diri dalam belajar. Penelitian ini dilatarbelakangi oleh banyaknya temuan penurunan hasil belajar matematika siswa dari hasil observasi awal penelitian. Sehingga penelitian ini dilakukan dengan tujuan mengetahui pengaruh penggunaan metode pembelajaran demonstrasi dan metode $\mathrm{drill}$.

SD Cenderawasih 2 Jakarta kelas IV semester genap tahun ajaran 2019-2020 sebagai tempat melakukan penelitian. Metode eksperimen digunakan dalam penelitian ini. Populasi penelitian yaitu seluruh siswa kelas IV, kemudian dipilih sampel secara acak. Kelas eksperimen terdiri dari 30 sampel dan kelas kontrol sebanyak 30 siswa. Intrumen penelitian telah dilakukan uji validitas dengan rumus Point Biserial Correlation didapat 30 soal yang valid dan uji reliabilitas, sementara uji reliabilitas menggunakan KR-20 diperoleh $r_{\text {hitung }}=0,894>0,361=r_{\text {tabel }}$. Kedua data dilakukan uji lanjutan yaitu normalitas maupun uji homogenitas. Hasil uji normalitas pada kelas eksperimen diperoleh $L_{\text {hitung }}=0,110<0,161=L_{\text {tabel }}$ sementara kelas kontrol $L_{\text {hitung }}=0,063<0,161=L_{\text {tabel }}$, sehingga
\end{abstract} kedua sampel dapat disimpulkan berdistribusi normal. Hasil perhitungan uji homogenitas dihasilkan 
$F_{\text {hitung }}=1,095<1,861=F_{\text {kritis }}$, sehingga kedua kelas tersebut dapat disimpulkan mempunyai varians homogen. Hasil pengujian hipotesis dengan uji-t didapat $t_{\text {hitung }}=2,389>2,002=t_{\text {krits }}$ taraf signifikansi $\alpha=0,05$ serta derajat kebebasan $(\mathrm{dk})=58$. Maka tolak $\mathrm{H}_{0}$, sehingga hasil penelitian mengambil kesimpulan bahwa ada pengaruh terhadap hasil belajar matematika menggunakan metode demonstrasi dan metode drill.

\section{Kata kunci : metode demonstrasi, metode drill, hasil belajar matematika siswa.}

\section{PENDAHULUAN}

Matematika diajarkan disemua jenjang pendidikan, sehingga termasuk pelajaran yang penting untuk dikuasai. Tuntutan serta tantangan yang dihadapi peserta didik dalam arus global mengharuskan seorang pendidik matematika untuk mencari strategi dalam mempersiapkan peserta didik yang berkualitas. Tanpa bantuan konsep dalam matematika dan proses matematika yang mendasar peserta didik akan banyak mendapat kesulitan. Siswa SD masih ada yang cukup mengalami kesulitan dalam belajar matematika sehingga mempengaruhi hasil belajar matematika dan pelajaran lain yang berkaitan dengan kemampuan matematik. Beberapa analisis yang dapat dilihat mengenai kesulitan belajar dikarenakan; kesulitan memahami konsep, kesulitan mengingat rumus, kesulitan dalam memahami soal cerita (Waskitoningtyas, 2016). Hal ini terlihat dari hasil proses belajar untuk subpokok bahasan bangun datar tahun ajaran sebelumnya, di mana tidak sedikit siswa belum mencapai batas ketuntasan materi.

Menurut Djamarah dan Zain menjelaskan bahwa metode pembelajaran sebuah sarana atau alat untuk memotivasi dalam mencapai tujuan pembelajaran (Nasution, 2017). Kurang tepatnya guru dalam menggunakan metode pembelajaran akan berdampak terhadap hasil belajar siswa. Teori Piaget menjelaskan bahwa peserta didik tingkat dasar berada pada tahap kongrit, sehingga dalam menanamkan konsep hendaknya menggunakan bantuan objek nyata agar lebih mudah diterima (Arifuddin \& Arrosyid, 2017). Dalam kegiatan pembelajarnya peserta didik menjadi subjek yang melakukan pengamatan maupun eksperimen untuk menemukan pemahaman konsep, guru bertugas sebagai fasilitator dalam membantu mengarahkan kegiatan peserta didik. Proses pembelajaran yang melibatkan semua peserta didik untuk ikut langsung akan lebih menanamkan konsep yang diterima peserta didik sehingga akan tertanam dalam otak peserta didik.

Berdasarkan observasi awal yang telah dilakukan peneliti terhadap beberapa guru di kelas IV SD terkait hasil pembelajaran matematika siswa di tahun pembelajaran 2018/2019 pada pokok bahasan bangun datar di dapatkan bahwa 52\% siswa nilai ulangan harian dibawah KKM. Setelah dilakukan wawancara kepada peserta didik, mereka mengalami kendala dalam memahami kharakteristik bangun datar yang dirasa hampir sama, kesulitan menghapal rumus, serta dalam memecahkan soal cerita. Proses dalam pembelajaran jika dilakukan oleh peserta didik secara langsung dalam melakukan ekperimen menggunakan benda nyata yaitu metode demonstrasi. Menurut Sanjaya (2009) metode demontrasi merupakan pembelajaran melalui cara memperagakan serta menunjukan langsung kepada peserta didik mengenai sifat-sifat yang dimiliki materi pembelajaran (dalam Arifuddin et al., 2018). Dengan metode demontrasi suasana pembelajaran dapat lebih hidup dan memberikan pengalaman belajar dengan melihat maupun mendengarkan serta melakukan secara langsung. 
Selain metode demonstrasi, guru dapat menggunakan metode drill dalam proses pembelajarn matematika. Menurut Sriyono bahwa drill merupakan latihan melalui praktek yang dilakukan terus menerus secara berulang serta berkelanjutan sehingga peserta didik dapat memiliki keterampilan, ketangkasan, kesempatan dan ketepatan (dalam Wahyuni, 2013) dalam mengerjakan soal-soal matematika khusunya dalam materi bangun datar. Latihan soal akan membuat siswa terbiasa mengerjakan soal dengan cepat, apalagi jika siswa sudah mengerti prosedur pengerjaanya. Untuk itu dengan waktu yang diberikan siswa dapat menyelesaikan soal-soal dengan baik. Ini dapat diartikan bahwa kemampuan matematik siswa tersebut masih kurang yang mengakibatkan terhadap hasil belajar dalam pelajaran matematika siswa yang bersangkutan juga rendah. Kemampuan matematika yang dimaksud adalah kemampuan dalam operasi atau prosedur dalam mengerjakan soal matematika agar siswa mampu mendapatkan hasil belajar yang optimal.

Penggunaan metode dalam pembelajaran baik demonstrasi maupun metode $d r i l l$ hasil yang diharapkan yaitu terjadi peningkatan interaktif guru dengan peserta didik dengan harapan hasil belajar matematika peserta didik dapat meningkat.. Hasil dari belajar merupakan output dari sebuah proses pembelajaran yang dilakukan siswa bisa erupa nilai maupun huruf (Sembiring, Rosali, 2013). Dengan hasil belajar seorang pendidik dapat melakukan refleksi mengenai pembelajaran yang sudah dilaluinya sehingga ketika ada kekurangan dapat segera dilakukan perbaikan. Sehingga guru dapat mempertimbangkan pemilihan metode dalam mengajar dengan harapan dapat meningkatkan hasil pembelajaran. Metode pembelajaran yang interaktif dapat meningkatan hasil belajar matematika karena adanya keterlibatan siswa langsung melakukan proses belajar (Egok, 2016).

Bertolak dari beberapa permasalah hasil observasi awal, serta kajian teori yang telah dilakukan, maka dilakukan sebuah penelitian terkait metode pembelajaran demonstrasi dan metode drill dalam meningkatkan hasil pembelajaran matematika siswa sekolah dasar kelas IV pada pokok bahasan bangun datar.

\section{METODOLOGI}

\subsection{Metodologi Penelitian}

Metode yang digunakan dalam penelitian adalah Quasi Eksperimental Design. Metode demonstrasi digunakan kepada kelas eksperimen, sementara kelas kontrol menggunakan metode drill. Maka pola penelitian (Arikunto, 2010) yang sesuai dengan penelitian adalah:

\begin{tabular}{|lll|}
\hline $\mathrm{E}$ & $X_{1}$ & $Y_{1}$ \\
\cline { 2 - 3 } $\mathrm{K}$ & $X_{2}$ & $Y_{2}$ \\
\hline
\end{tabular}

\section{Desain Penelitian}

Keterangan :

$E$ : Kelas eksperimen

$K$ : Kelas kontrol

$X_{1}$ : Metode demonstrasi kelas eksperimen 
$X_{2}$ : Metode drill kelas kontrol

$Y_{1}$ : Hasil belajar kelas eksperimen

$Y_{2}$ : Hasil belajar kelas kontrol

Populasi merupakan semua objek dalam penelitian. Target populasi seluruh siswa SD Cenderawasih 2 Jakarta yang terdaftar sebagai siswa di semester genap tahun ajaran 2019-2020 yang diberikan pelajaran matematika. Populasi terjangkau adalah seluruh peserta didik di kelas IV SD Cenderawasih 2 Jakarta yang terdaftar pada semester genap pada tahun ajaran 2019-2020. Sampel terdiri dari dua kelas, kemudian diambil secara acak dan dihasilkan kelas IV-A dan kelas IV-B. Kelas IV-A berjumlah 30 siswa sebagai kelompok eksperimen sementara kelas IV-B berjumlah 30 siswa sebagai kelompok kontrol. Dari masing-masing kelompok diambil secara keseluruhan sebanyak 30 siswa sehingga jumlah sampel yang diambil sebagai objek penelitian sebanyak 60 siswa.

\subsection{Teknis Pengumpulan Data}

Data penelitian dihasilkan dari test belajar matematika siswa kedua kelas setelah mendapat perlakuan yang berbeda yaitu metode demonstrasi terhadap kelas eksperimen (IV-A) dan metode drill pada kelas control (IV-B). Tes berjumlah 30 soal pilihan ganda yang sebelumnya sudah dilakukan uji validitas dengan kolerasi Point Biserial (Arikunto, 2010) dan uji reliabilitas dengan metode dari KR-20 (Purwanto, 2009)

\subsection{Teknik Analisi Data}

Teknik analisis data untuk menguji terdapat perbedaan atau tidak hasil belajar matematika siswa kelas ekperimen maupun kelas kontrol maka digunakan statistik dekriptif yaitu rata-rata, median, modus dan simpangan baku. Kemudian dilanjutkan dengan melakukan uji normalitas serta uji homogenitas untuk membuktikan bahwa kedua kelas berada pada data yang berditribusi normal dan homogen.

Uji hipotesis dilakukan dengan uji-t dengan kriterian terima $\mathrm{H}_{0}$ jika $\mathrm{t}_{\text {hitung }} \leq \mathrm{t}_{\text {tabel }}$ artinya tidak ada perbedaan antara hasil belajar matematika siswa dengan metode demonstrasi dan metode drill. Sementara tolak $\mathrm{H}_{0}$ jika $\mathrm{t}_{\text {hitung }}>\mathrm{t}_{\text {tabel }}$ maka terdapat perbedaan hasil belajar matematika siswa dengan metode demonstrasi dan metode drill.

\section{HASIL DAN PEMBAHASAN}

\subsection{Uji Coba Instrumen}

Setelah uji coba instrumen dilakukan diketahui bahwa dari 40 soal uji coba instrumen terdapat 30 soal yang valid, dan 10 soal yang tidak valid. Dengan $r_{\text {hitung }}=0,524$ dan $\mathbf{r}_{\text {tabel }}$ $=0,361$. Dan didapat reliabilitas $=0,894$, dengan $r_{\text {tabel }}=0,361$, karena di $r_{\text {hitung }}=0,894$ $>0,361=r_{\text {tabel }}$ maka soal instrumen dinyatakan reliabel. Maka instrumen yang dapat digunakan dalam penelitian berjumlah 30 soal.

\subsection{Deskripsi Data}

Kelas eksperimen yang diajarkan dengan metode demonstrasi didapatkan skor terendah 14 dan skor tertinggi 28 dengan jumlah sampel 30. Mean 22,067 dan simpangan baku 4,034, median 22,3 dan modus 23. Kelas kontrol yang diajarkan dengan metode drill didapatkan nilai terendah 12 dan nilai tertinggi 26 dengan jumlah sampel 30. Mean 19,633 dan simpangan baku 3,855, median 22,167 dan modus 21 . 


\subsection{Pengujian Hipotesis}

Uji prasyarat analisis data yaitu uji homogenitas serta normalitas diperoleh bahwa kelas eksperimen dan kelas kontrol berada pada sampel yang berdistribusi normal, sehingga dapat melakukan pengujian hipotesis yaitu menggunakan uji-t.

Perbedaan rerata dari perhitungan antara kelas eksperimen dan kelas kontrol diperoleh $t_{\text {hitung }}=2,389$. Sedangkan pada taraf signifikansi $\alpha=0,05 \mathrm{dan} \mathrm{dk}=58$ diperoleh $t_{\text {kritis }}=2,002$. Kriteria pengujian adalah tolak $\mathrm{H}_{0}$ jika $t_{\text {hitung }}>t_{\text {kritis. }}$ Karena $t_{\text {hitung }}=2,389$ $>2,002=t_{k r i t i s}$, maka terima $\mathrm{H}_{1}$. Sehingga menunjukkan bahwa terdapat perbedaan hasil pembelajaran matematika siswa antara yang menggunakan metode demonstrasi dan metode drill.

\subsection{Pembahasan}

Metode demonstrasi salah satu metode yang bisa digunakan dalam proses pembelajaran, dimana dengan metode demonstrasi siswa dapat melihat langsung objek pembelajaran sehingga dalam memahami akan lebih mudah. Metode demonstrasi dapat membantu siswa dalam memahami materi pelajaran (Asni Bartik, Abdussamad, 2013). Ikut sertanya siswa dalam pembelajaran menggunakan metode demonstrasi diharapkan dapat meningkatkan motivasi siswa dan terjadinya elaborasi kognitif siswa (Syahputri, 2018).

Berdasarkan hasil analisis data penelitian dapat dilihat bahwa hasil pengujian hipotesis pertama menunjukan terdapat pengaruh hasil pembelajaran matematika siswa menggunakan dengan metode demonstrasi dan metode drill. Hal ini didukung oleh perolehan persentase hasil pembelajaran matematika kelompok eksperimen yaitu kelompok siswa yang diajarkan menggunakan metode demonstrasi sebesar 73,5\%, lebih besar dari kelompok kelas kontrol yaitu kelompok siswa menggunakan pembelajaran metode drill sebesar $65,4 \%$. Hal ini sejalan dengan hasil penelitian Ovilia bahwa metode demontrasi mampu meningkatkan hasil belajar (Gumay \& Bertiana, 2018). Serta penelitian yang dilakukan Eli Dwi Susanti dengan metode demonstrasi siswa lebih antusias dan interaktif sehingga mampu meningkatkan hasil belajar (Susanti, 2015). Fenomena ini menunjukan bahwa ternyata hasil pembelajara siswa dengan menggunakan metode demonstrasi pada pokok bahawan bangun datar menunjukan nilai yang lebih besar dibandingkan dengan siswa yang menggunakan metode drill, kendati demikian metode demonstrasi belum mencapai ketuntasan persentase hasil belajar yang ideal sesuai KTSP yaitu $75 \%$.

\section{SIMPULAN}

Berdasarkan hasil analisis data yang telah dilakukan terhadap kelas ekperimen maupun kelas kontrol menunjukan adanya perbedaan dari hasil belajar matematika siswa. Penggunaan metode pembelajaran dapat mempengaruhi proses maupun hasil pembelajaran. Hasil pembelajaran matematika siswa menggunakan metode demonstrasi lebih tinggi dibandingkan dengan metode drill pada pokok bahasan bangun datar.

Hasil reflkesi setelah pembelajaran berlangsung bahwa siswa dengan menggunakan metode demonstrasi lebih memahami karena melihat objek yang dipelajari secara langsung. Sehingga lebih mudah dalam mengkontruksi pemahaman materi. Metode drill lebih cocok digunakan untuk materi yang bersifat perhitung, karena dilakukan berulang- 
ulang. Siswa yang melakukan banyak latihan soal-soal akan lebih mahir dan lebih menguasai materi pembelajaran dengan baik.

\section{DAFTAR PUSTAKA}

Arifuddin, A., \& Arrosyid, S. R. (2017). Pengaruh Metode Demonstrasi dengan Alat Peraga Jembatan Garis Bilangan Terhadap Hasil Belajar Matematika Materi Bilangan Bulat. Al Ibtida: Jurnal Pendidikan Guru MI, 4(2), 165. https://doi.org/10.24235/al.ibtida.snj.v4i2.1834

Arifuddin, A., Maufur, S., \& Farida, F. (2018). Pengaruh Penerapan Alat Peraga Puzzle dengan Menggunakan Metode Demonstrasi Terhadap Motivasi Belajar Siswa Pada Pembelajaran Matematika di SD/MI. Jurnal Ilmiah Sekolah Dasar, 2(1), 10. https://doi.org/10.23887/jisd.v2i1.13721

Arikunto, S. (2010). Dasar-Dasar Evaluasi Pendidikan. Bumi Aksara.

Asni Bartik, Abdussamad, R. (2013). Peningkatan Aktivitas Pembelajaran Matematika dengan Penerapan Metode Demonstrasi di Kelas III SDN 11 Sungai Kunyit. Jurnal Pendidikan Dan Pembelajaran, 84, 487-492. http://ir.obihiro.ac.jp/dspace/handle/10322/3933

Egok, A. S. (2016). Kemampuan berpikir kritis dan kemandirian belajar dengan hasil belajar matematika. Jurnal Pendidikan Dasar, 7(2), 186.

Gumay, O. P. U., \& Bertiana, V. (2018). Pengaruh Metode Demonstrasi terhadap Hasil Belajar Fisika Kelas X MA Almuhajirin Tugumulyo. Science and Physics Education Journal (SPEJ), 1(2), 96-102. https://doi.org/10.31539/spej.v1i2.272

Nasution, M. K. (2017). Penggunaan metode pembelajaran dalam peningkatan hasil belajar siswa. STUDIA DIDAKTIKA: Jurnal Ilmiah Bidang Pendidikan, 11(1), 9-16.

Purwanto, N. (2009). Prinsip-Prinsip dan Teknik Evaluasi Pengajaran. Remaja Rosdakarya.

Sembiring, Rosali, M. (2013). Strategi Pembelajaran Dan Minat Belajar Terhadap Hasil Belajar Matematika. Jurnal Teknologi Pendidikan (JTP), 6(2), 34-44. https://doi.org/10.24114/jtp.v6i2.4996

Susanti, E. D. (2015). Pengaruh Model Pembelajaran Problem Based Instruction Disertai Metode Demonstrasi Terhadap Hasil Belajar Dan Retensi Hasil Belajar Siswa Pada Pembelajaran Fisika Sma (Studi Pada Kelas X Mia Sman Arjasa Jember). Jurnal Pembelajaran Fisika, Vol 4 No 3. Desember 2015, Hal 255-260, 4(3), 255-260.

Syahputri, N. (2018). Rancang Bangun Media Pembelajaran Matematika Sekolah Dasar Kelas 1 Menggunakan Metode Demonstrasi. JSIK (Jurnal Sistem Informasi Kaputama), 2(1), 89-95. 
Wahyuni, N. (2013). Penggunaan metode drill dalam pembelajaran matematika. 02, 399406.

Waskitoningtyas, R. S. (2016). Analisis Kesulitan Belajar Matematika Siswa Kelas V Sekolah Dasar Kota Balikpapan Pada Materi Satuan Waktu Tahun Ajaran 2015/2016. JIPM (Jurnal Ilmiah Pendidikan Matematika), 5(1), 24. https://doi.org/10.25273/jipm.v5i1.852 